\title{
Compensation and the Twin Producer Gains from Production Quotas
}

\author{
Troy G. Schmitz ${ }^{1}$, Andrew Schmitz ${ }^{2}$ \\ ${ }^{1}$ Morrison School of Agribusiness and Resource Management, Arizona State University, Mesa, Arizona \\ ${ }^{2}$ Food and Resource Economics, IFAS, University of Florida, Gainesville, USA \\ E-mail: tschmitz@asu.edu, aschmitz@ufl.edu \\ Received June 21, 2011; revised August 12, 2011; accepted August 22, 2011
}

\begin{abstract}
The limited theory on production quotas focuses on the impact of introducing quotas when otherwise the market would be competitive. We develop a model also on the effect of removing quotas, and then consider the combined effects of both introducing and removing quotas. Under the value of quota approach, the amount of money spent by the government for the buyout (i.e., value of quota) is equal to the sum of the net gain to producers when the quota was introduced plus the net gain if it were removed. Compensation is the key to a quota buyout, as producers have little interest in politically supporting a government compensated buyout unless they gain by so doing.
\end{abstract}

Keywords: Compensation, Producer Gains, Production Quotas

\section{Introduction}

Theoretical studies on production quotas, such as those by Wallace [1]; Johnson [2]; Rucker, Thurman, and Sumner [3]; and Just, Hueth, and Schmitz [4], focus on the impact of production quotas compared to a competetive situation. In addition, Schmitz and Schmitz [5] analyzed the impacts of removing production quotas with an empirical application to the removal of the U.S. production quota for peanuts. They found that farmer compensation for the buyout was based on the value of quota approach. Farmers will lobby for the method of payment that leads to their greatest benefit. Successful political rent-seeking behavior by farmers will lead to an outcome from a buyout that favors farmers relative to taxpayers (Vercammen and Schmitz [6]; Schmitz, Furtan, and Baylis [7]; Schmitz and Schmitz [5]). In this paper, we consider the twin producer gains from both the introduction and removal of quotas. Under one approach to compensation, producers gain from both the implementation of a quota and its removal. Under the value of quota approach, for example, the value of quota at the time of removal exactly equals the twin producer gains from the quota (i.e., the gain from introducing the quota plus the gain from removing it). Quotas when implemented can have a much larger impact on the welfare of producers than when they are removed, even though gains are present when quotas are introduced and are present when they are removed. In addition, consumers generally have much more to gain from a production quota buyout than do producers.

\section{Theoretical Model}

We present the theoretical discussion of the impact of production quotas on 1) producer welfare when quotas are introduced; 2) the effect of removing quotas; and 3) the combined impact of both introducing and removing quotas. In our analysis, we consider two periods where in period 1 the quotas are introduced and in period 2 they are removed.

\subsection{Period 1}

Consider Figure 1 where $S$ is the supply schedule for good $x$ and $D$ is the domestic demand. In the absence of a quota, the competitive price is $p_{0}$ and the corresponding output is $q_{0}$. Suppose we introduce a production quota that restricts output to $q_{1}$ : price increases from $p_{0}$ to $p_{1}$. As a result, producers gain $\left(p_{1} p_{0} d a-d c b\right)$-a result often ignored in the discussion of production quotas. Producer welfare results are derived by comparing the competitive equilibrium price $p_{0}$ and quantity $q_{0}$ with the quota price $p_{1}$ and quantity $q_{1}$. 


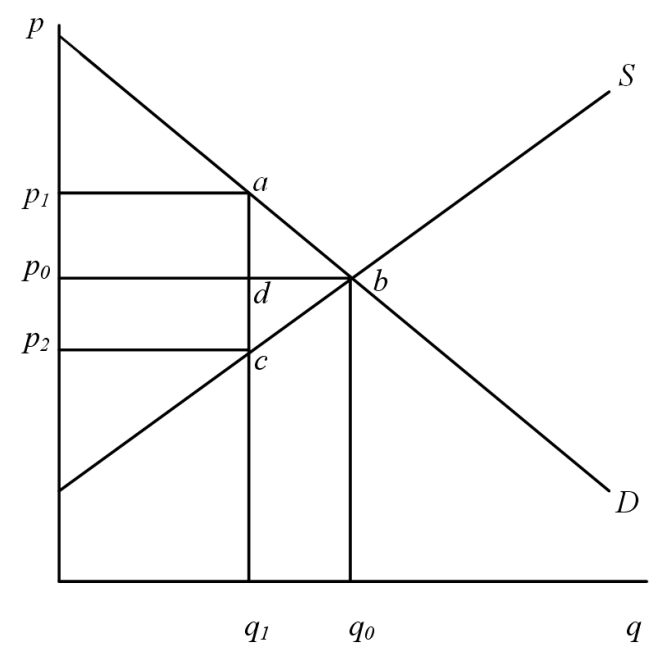

Figure 1. Government quota buyout.

Under the quota, consumers pay a higher price for the product which translates into a transfer to producers. The cost to consumers from the quota is $\left(p_{1} p_{0} b a\right)$ while the net societal cost is $(a c b)$.

\subsection{Period 2}

Here the government terminates (through a government-financed buyout compensation scheme) the quota program to restore price $p_{0}$ and quantity $q_{0}$. We examine two extreme alternatives that the government might use in making compensation payments: 1) the government pays the value of quota (Vercammen and Schmitz [6]; Schmitz and Schmitz [5]), which is $\left(p_{1} p_{2} c a\right)$, or 2) the government pays the producers $\left(p_{1} p_{0} d a-d c b\right)$, which is the gain from quota. Under 1$)$, the net producer gain is positive, $\left(p_{0} p_{2} c d+d c b\right)$, and is equal to $\left(p_{0} p_{2} c b\right)$. Under 2 ), the net producer gain is zero.

\subsection{Combined Effects}

There is no literature that analyzes the combined effect of both introducing and removing quotas. This is not surprising given that very little is written on the theory of quota buyouts. What is the combined effect on producers from both the introduction of the quota and from its removal? Under either approach to compensation discussed above, the net producer gain from the combined introduction and removal of the quota is at least as great as a gain from the introduction of the quota alone. The results are as follows:

Proposition (1): If producers are paid the value of quota, they gain from quota removal. However, they also gained at the time that the quota was introduced (the value of quota can be far greater than what producers can gain from its removal). For a two-period analysis, given a production quota and identical demand elasticities and supply elasticities for the two periods, the producer gain from introducing the quota plus the gain from removing it is equal to the value of quota. This is the amount that the government pays for the quota buyout. This can be demonstrated as follows:

1) The gain to producers from the quota buyout is $\left(p_{0} p_{2} c d+d c b\right)$

2) The net producer gain from introducing the quota is $\left(p_{1} p_{0} d a-d c b\right)$

3) The sum of items 1 and 2 above equals $\left(p_{1} p_{0} d a+\right.$ $\left.p_{0} p_{2} c d\right)$

4) Item 3 above equals the value of quota $\left(p_{1} p_{2} c a\right)$

Proposition (2): If producers are paid the gains from quota, the net producer gain is zero. However, they gained at the time that the quota was introduced. For a given production quota and identical demand elasticities and supply elasticities, the producer gain from introducing the quota plus the gain from removing it is equal to the gains from quota. This is the amount that the government pays for the quota buyout. This can be demonstrated as follows:

1) The net producer gain from the quota buyout is $\left(p_{1} p_{0} d a-d c b\right)+\left(-p_{1} p_{0} d a+d c b\right)$

2) The net gain to producers from quota implementation is $\left(\mathrm{i}_{1} p_{0} d a-d c b\right)$

3) The sum of items 1 and 2 above equals ( $p_{1} p_{0} d a-$ dcb)

4) Item 3 above equals the gains from quota $\left(p_{1} p_{0} d a-\right.$ $d c b)$

In the above, quotas when they are implemented generate producer gains that are paid for through higher consumer prices. However, when they are removed (and paid under the value of quota), the producer gains result from treasury expenditures from the buyout.

In our model, given identical supply and demand conditions, when the quota is implemented and when it is removed, the value of quota reflects producer gains from both the introduction and removal of the quota-not just the value to producers when removing the quota. Generally, the gains from the introduction of quota are greater than the gains from its removal.

\section{Concluding Comments}

It is common with quota buyouts that the payout be based on the value of quota approach, where producers gain from the buyout and also gain at the expense of taxpayers. We emphasize that the producers gain from both the removal of the quota and its introduction. Under certain conditions, the sum of these two gains is exactly equal to the value of the production quota that exists 
when the quota is removed. Quota values are not a measure of the net gain to producers from a quota buyout even though many policy analysts continue to believe so.

When assessing the magnitude of compensation, it is important to consider both the introduction and removal of quotas, otherwise one is left with the wrong impresssion of the size of the payout based on the value of the quota. When considering both of the components, the size of the compensation can be large. But, this result is not surprising in view of the many packages that have been put together to compensate losers from a change in policy (Schmitz and Zerbe [8]).

\section{References}

[1] T. D. Wallace, "Measures of Social Costs of Agricultural Programs,” Journal of Farm Economics, Vol. 44, No. 2, 1962, pp. 580-599. doi:10.2307/1235863

[2] P. R. Johnson, "The Social Cost of the Tobacco Program,” Journal of Farm Economics, Vol. 47, No. 2, 1965, pp. 242-255. doi:10.2307/1236572
[3] R. Rucker, W. Thurman and D. Sumner, "Restricting the Market for Quota: An Analysis of Tobacco Production Rights with Corroboration from Congressional Testimony,” Journal of Political Economy, Vol. 103, No. 1, 1995, pp. 142-175. doi:10.1086/261979

[4] R. E. Just, D. L. Hueth and A. Schmitz, "The Welfare Economics of Public Policy: A Practical Approach to Project and Policy Evaluation,” Edward Elgar Publishing, Cheltenham, 2004.

[5] A. Schmitz and T. G. Schmitz, "Benefit-Cost Analysis: Distributional Considerations under Producer Quota Buyouts,” Journal of Benefit-Cost Analysis, Vol. 1, No. 1, 2010, Article 2.

[6] J. A. Vercammen and A. Schmitz, "Supply Management and Import Concessions," Canadian Journal of Economics, Vol. 25, No. 4, 1992, pp. 957-971. doi:10.2307/135774

[7] A. Schmitz, H. Furtan and K. Baylis, “Agriculture Policy, Agribusiness, and Rent-Seeking Behaviour,” University of Toronto Press, Toronto, 2002.

[8] A. Schmitz and R. O. Zerbe Jr., "Applied Benefit-Cost Analysis,” Edward Elgar Publishing, Cheltenham, 2008. 